Review

\title{
Advanced Endoscopic Techniques in the Evaluation and Treatment of Fibrostenotic Crohn's Disease
}

Alina Wong ${ }^{\dagger, *}$, Scott D Lee ${ }^{\dagger}$

Division of Gastroenterology, Department of Medicine, University of Washington Medical Center, Seattle, WA, USA; E-Mails: abwong@medicine.washington.edu; ScottL@medicine.washington.edu

+ These authors contributed equally to this work.

* Correspondence: Alina Wong; E-Mail: abwong@medicine.washington.edu

Academic Editor: Tony C. K. Tham

Special Issue: New and Old Therapeutic Options for Crohn's Disease

OBM Hepatology and Gastroenterology

2019, volume 3 , issue 3

doi:10.21926/obm.hg.1903033
Received: May 09, 2019

Accepted: August 13, 2019

Published: August 16, 2019

\begin{abstract}
Crohn's disease is characterized by chronic intestinal inflammation that can result in significant morbidity and loss of intestinal function over time. Many novel treatments for Crohn's disease are being developed, but a significant portion of patients still requires surgical therapy for stricturing or penetrating disease. Classically esophagogastroduodenoscopy and ileocolonoscopy have been used to diagnose patients with inflammatory bowel disease and to restage disease after starting or changing therapy. However, new endoscopic techniques are being developed to help evaluate previously inaccessible parts of the small intestine and to treat fibrostenotic complications. This review will focus on video capsule endoscopy, small bowel enteroscopy, endoscopic balloon dilation, as well as other more novel investigational endoscopic therapies for the evaluation and treatment of fibrostenotic complications.
\end{abstract}

\section{Keywords}

Crohn's disease; endoscopy; fibrostenotic complications

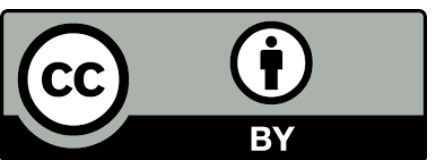

(C) 2019 by the author. This is an open access article distributed under the conditions of the Creative Commons by Attribution License, which permits unrestricted use, distribution, and reproduction in any medium or format, provided the original work is correctly cited. 


\section{Introduction}

Crohn's disease is a chronic inflammatory bowel disease that when inadequately treated results in progressive transmural complications such as strictures, fistulas, and abscesses. While the majority of patients present with non-penetrating disease at diagnosis, around $50-60 \%$ develop fibrostenotic disease over time [1]. Endoscopy serves an important role in the diagnosis, management, and treatment of inflammatory bowel disease. It not only helps distinguish between Crohn's disease and ulcerative colitis, but also allows for the diagnosis and management of fibrostenotic complications. Endoscopic therapy, a less invasive alternative to surgical options, bridges the gap between medical and surgical treatments. Endoscopic tools include video capsule endoscopy, small bowel enteroscopy, endoscopic balloon dilation, as well as other more novel investigational therapies. This review will focus on using advanced endoscopic therapeutic techniques for the diagnosis and management of fibrostenotic complications in Crohn's disease (Table 1).

Table 1 Advanced endoscopic techniques for the assessment and treatment of fibrostenotic complications.

\begin{tabular}{|c|c|c|}
\hline & Indications & Disadvantages \\
\hline $\begin{array}{l}\text { Small bowel } \\
\text { capsule endoscopy }\end{array}$ & $\begin{array}{l}\text { Evaluation of small bowel segments } \\
\text { inaccessible by standard endoscopy }\end{array}$ & Capsule retention \\
\hline $\begin{array}{l}\text { Small bowel } \\
\text { enteroscopy }\end{array}$ & $\begin{array}{l}\text { Biopsy/resection of small bowel } \\
\text { lesions } \\
\text { Therapeutic intervention on } \\
\text { fibrostenotic disease }\end{array}$ & $\begin{array}{l}\text { Invasive } \\
\text { Technically challenging } \\
\text { Complications include bleeding, perforation, } \\
\text { ileus, pancreatitis }\end{array}$ \\
\hline Balloon dilation & Short uncomplicated strictures & $\begin{array}{l}\text { Complications include bleeding, perforation, } \\
\text { and infection }\end{array}$ \\
\hline $\begin{array}{l}\text { Self expanding } \\
\text { metal stents }\end{array}$ & Recurrent or refractory strictures & $\begin{array}{l}\text { Complications include bleeding, perforation, } \\
\text { infection, and stent migration }\end{array}$ \\
\hline $\begin{array}{l}\text { Endoscopic } \\
\text { stricturotomy }\end{array}$ & Short uncomplicated strictures & $\begin{array}{l}\text { Technically challenging } \\
\text { Requires extensive training } \\
\text { Complications include bleeding, perforation, } \\
\text { and infection }\end{array}$ \\
\hline
\end{tabular}

\section{Small Bowel Capsule Endoscopy}

The small bowel is affected in up to 70\% of patients with Crohn's disease [2]. While most areas of inflammation can be reached by conventional endoscopy, up to $30 \%$ of patients have isolated small bowel disease out of reach of conventional endoscopy [3]. Patients with proximal small bowel involvement have worse long term prognosis and are at increased risk of complications [4]. It is important to identify these patients early to alter management appropriately. 
Small bowel capsule endoscopy (SBCE) allows complete visualization of the entire small bowel mucosa. Findings associated with Crohn's disease include erosions, aphthous lesions, deep ulcers, loss of normal villi and vascular pattern, as well as luminal strictures or fistulae. The main risk of SBCE is capsule retention and the subsequent potential need for surgical retrieval. The incidence of capsule retention is estimated at $1.5 \%$ [5]. The main risk factors for capsule retention include Crohn's disease related strictures, anastomotic strictures, and small bowel tumors. Cross sectional imaging or a patency capsule should be considered in patients with clinical signs of strictures. A patency capsule is similar in size to a capsule endoscope but is self-dissolvable in the event of retention. This allows for the assessment of the risk of capsule retention prior to administration of SBCE.

The contribution of SBCE for the diagnosis of small bowel involvement has been compared to other modalities. A meta-analysis of 30 prospective trials found that the diagnostic yield of SBCE was superior to small bowel radiography, CT enteroclysis, colonoscopy with ileoscopy, push enteroscopy, and MR enterography (MRE) in patients with suspected and established Crohn's disease [3]. Compared to the other modalities, SBCE was better at detecting early small bowel lesions [6] even when laboratory markers and clinical symptoms were not suggestive of active disease. A retrospective multicenter study by Kopylov et al evaluated 187 patients with established Crohn's disease who underwent SBCE and compared the results to inflammatory biomarkers. This study found that c-reactive protein (CRP) and fecal calprotectin were poorly correlated with significant small bowel inflammation [7]. Similarly, a prospective trial by the same author found that $85 \%$ of patients with known small bowel disease in clinical remission based on Crohn's Disease Activity Index $($ CDAl $<150)$ had evidence of active inflammation with SBCE compared to $60 \%$ with either elevated CRP or fecal calprotectin and $77 \%$ with MRE [8].

SBCE is likely the most sensitive measurement of active disease in the small intestine out of reach of standard ileocolonoscopy especially when compared to biochemical markers or cross sectional imaging. Given Crohn's disease can progress in a fibrostenotic course, SBCE is potentially a useful tool to diagnose persistent active inflammatory small bowel disease early to modify therapy and prevent complications. However, more studies are needed to assess whether treating the findings on SBCE will actually change patient outcomes.

\section{Small Bowel Enteroscopy}

A limitation of capsule endoscopy is its inability to provide tissue for histological evaluation or to perform endoscopic therapy. Single balloon enteroscopy (SBE) was first described in 2001 as a new method to evaluate the small bowel [9]. Since then, single balloon and double balloon techniques have been developed. With both techniques, one or two balloons are inflated and deflated in order to pleat the small bowel over the endoscope. This allows the enteroscope to advance further into the small bowel than would be feasible with standard endoscopy. Potential therapeutic advantages include the ability to evaluate atypical lesions, obtain biopsies, and intervene therapeutically. However, due to SBE's invasive nature, technical difficulty, and other alternative less invasive modalities, American College of Gastroenterology guidelines only recommend SBE be used if it has the potential to alter medical therapy or if it allows for endoscopic intervention [10]. SBE should not be routinely used for the diagnosis of small bowel Crohn's disease. 
The diagnostic yield of SBE in patients with known or suspected Crohn's disease has been reported as high as $\sim 80 \%$ [11-13]. A multicenter retrospective study looked at five large tertiary centers in the United States and determined a diagnostic yield of $87 \%$ in patients with known Crohn's disease and 79\% in patients with suspected Crohn's disease [11]. While the overall numbers were small $(n=81)$, double balloon enteroscopy was noted to impact management in $79 \%$ of patients. This included changing Crohn's related therapy, diagnosing mass lesions, excluding small bowel Crohn's disease, removing retained video capsules, and treating strictures (Figure 1).

Figure 1 Inflammatory lesions discovered on small bowel enteroscopy.

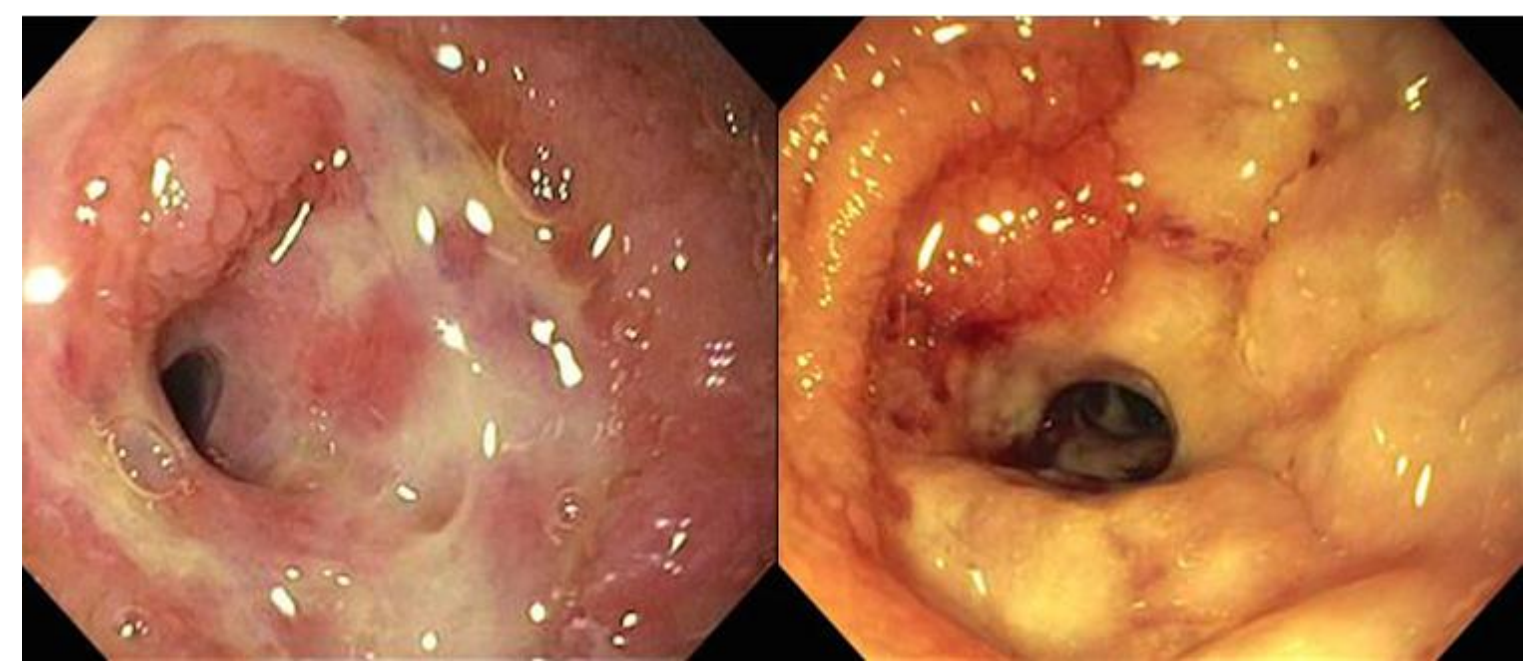

Caption: Proximal jejunal (A) and distal jejunal (B) lesions visualized using double balloon enteroscopy.

Several studies have evaluated the utility of SBE for the treatment of Crohn's related strictures $[14,15]$. One prospective study assessed the feasibility and effectiveness of Crohn's disease related small bowel stricture dilation using double balloon enteroscopy [14]. In this study, eighteen small-bowel stricture dilations were performed in 11 patients. Stricture dilation was successful in $73 \%$ of patients with subsequent improvement in symptoms. Only one case was complicated by delayed perforation and two patients required repeat dilation because of symptom recurrence. While this is a small series, it suggests that small bowel enteroscopy with stricture dilation could be an effective alternative to surgery. A recent systematic review further evaluated the role of double balloon enteroscopy in small bowel strictures [16]. They looked at 13 retrospective studies. Among those who underwent small bowel enteroscopy, $80 \%$ achieved longterm success without the need for surgery. However, $20 \%$ did ultimately require surgery either due to complications of the enteroscopy or relapse of symptoms. The total complication rate per dilation was $2.6 \%$.

SBE bridges the gap between medical and surgical treatments and offers patients with fibrostenotic complications an alternative to surgery. Even if dilation is ineffective or results in a complication, the majority of these patients would likely eventually require surgical intervention. While surgery cannot always be avoided, it is associated with its own risks including short bowel syndrome, malnutrition, and Crohn's recurrence at the surgical site. Therefore, while there is 
limited data and more studies are needed, we would recommend consideration of dilation with the aid of SBE prior to surgery for strictures not within reach of standard endoscopy.

\section{Balloon Dilation}

Fibrostenotic disease can significantly reduce quality of life as well as lead to complications such as small bowel obstructions, abscesses, and fistulas. While radiologic studies can suggest the presence of a stricture, endoscopy can both diagnose structural complications and provide therapeutic treatment options. Endoscopy can assess degree of active inflammation to guide medical therapy, biopsy to exclude malignancy, and treat fibrostenotic complications delivering symptomatic relief to the patient.

Strictures can occur in the large bowel, small bowel, as well as post-surgical anastomoses. They can be secondary to long standing active inflammation resulting in fibrosis and eventual stenosis, ischemia at post-surgical anastomoses, or infectious complications. They are classified based on location, degree of stenosis, length, number, and complexity (ie associated abscess or fistula tract) [17].

Endoscopic balloon dilation uses a through the scope balloon to dilate an area of stenosis usually to a maximum of 18 to $20 \mathrm{~mm}$ in diameter (Figure 2). Success is defined based on technical and clinical outcomes. Features that predict technical success include stricture length less than four to five centimeters, minimal inflammation, lack of stricture angulation, and lack of associated fistula or abscess $[18,19]$.

Figure 2 Endoscopic balloon dilation of a large bowel stricture.

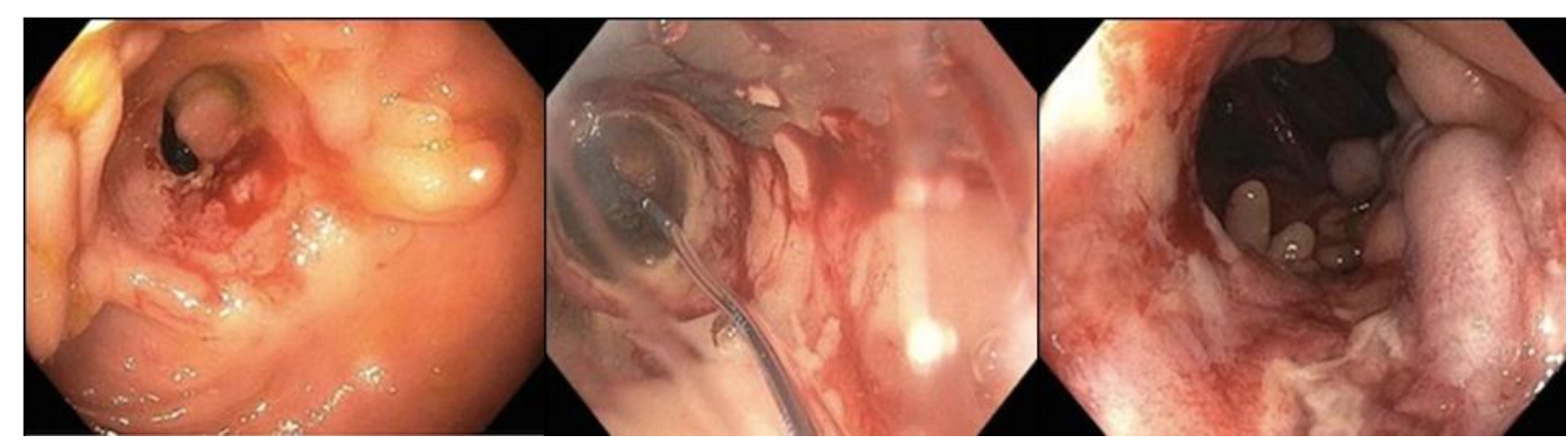

Caption: Colonic stricture prior to endoscopic balloon dilation (A), intra endoscopic balloon dilation (B), and post endoscopic balloon dilation (C).

We recommend that patients with suspected stricture are first evaluated with cross sectional imaging in order to assess for high risk lesions. Balloon dilation should be avoided in patients with associated fistulous tracts. While angulation is a relative contraindication to balloon dilation, intraprocedural fluoroscopic guidance can assist with the safe passage of the balloon across an angulated stricture.

A recent systematic review, evaluating over 3000 endoscopic balloon dilation procedures, determined a technical success rate of $89 \%$ and clinical success rate of $81 \%$ [20]. $74 \%$ of patients required repeat dilation and $43 \%$ ultimately underwent surgical resection after 24 months of follow-up [20]. In a study comparing endoscopic dilation to surgery for anastomotic strictures, the average time to surgery was deferred by 6.45 years [21]. Overall, rates of complication range from 
approximately 0.3 to $6 \%$ depending on the study [20-23]. In select patients, endoscopic balloon dilation has a high technical and clinical success rate that can improve patient symptoms and delay and at times avoid surgical intervention (Table 2).

Table 2 Reported outcomes in the endoscopic treatment of fibrostenotic disease by treatment modality.

\begin{tabular}{|l|l|l|l|}
\hline & Endoscopic efficacy & Need for repeat procedure & Adverse events $^{\text {D }}$ \\
\hline $\begin{array}{l}\text { Balloon dilation } \\
{[\mathbf{2 0}, \mathbf{2 3}, \mathbf{3 2}-35]}\end{array}$ & $74-97 \%$ & $38-74 \%$ & $0.3-6.4 \%$ \\
\hline SEMS [29] ${ }^{\text {A, B }}$ & $92 \%$ & $53 \%$ & $4 \%$ \\
\hline $\begin{array}{l}\text { Endoscopic } \\
\text { stricturotomy [31] }\end{array}$ & $100 \%$ & $61 \%$ & $3.7 \%$ \\
\hline
\end{tabular}

${ }^{\text {A }}$ SEMS: Self expanding metal stents

${ }^{B}$ Based on data from the largest study to date evaluating 17 patients

${ }^{\mathrm{C}}$ Based on data from a single center study

${ }^{D}$ Main adverse events included perforation and bleeding

\section{New Investigational Therapies}

New endoscopic treatments are currently being investigated for fibrostenotic disease. These include mesenchymal stromal cells, endoscopic intralesional injection, endoscopic stents, and stricturoplasty.

Mesenchymal stromal cells are thought to affect anti-fibrogenic activity by reducing expression of fibrotic proteins. To date, this has only been studied in mice, but could serve as a potential therapy in the future [24]. Endoscopic intralesional injection of long acting cortiscosteroids has been attempted but results are contradictory with some studies showing an earlier need for repeat dilation $[25,26]$. Intralesional injection of anti-TNF agents has been described in small case series, but more studies need to be performed to investigate its true value [27].

Malignant strictures in the gastrointestinal tract are frequently treated with self expanding metal stents (SEMS). This technique has been studied in non-malignant diseases as well, including Crohn's disease. To date, SEMS have mainly been used in refractory or recurrent strictures not improved with endoscopic balloon dilation. Given endoscopically placed stents need to be removed in non-malignant diseases, covered metal stents are preferred. This was first described in a case series of two patients in 2000 [28]. Follow-up studies have also been small ranging from one to seventeen patients. The largest study retrospectively looked at 17 patients with strictures refractory to medical and or endoscopic treatment (Table 2) [29]. SEMS placement was technically successful in $92 \%$ of patients with clinical success rate of $65 \%$ with a mean follow-up period of 67 weeks. Only one patient had an adverse event due to proximal stent migration during insertion that required surgical intervention. Of note, 13 out of the 25 stents that were placed spontaneously migrated distally after insertion. While the theoretical advantage of endoscopic stents is that they allow for constant dilation of the stricture over a longer period of time, the PROTDILAT study prospectively compared preliminary data evaluating SEMS and endoscopic 
balloon dilation in 99 patients and found that endoscopic balloon dilation was more effective than stent placement [30]. Thus currently, balloon dilation remains the endoscopic treatment of choice for strictures, with SEMS reserved for recurrent or refractory cases. Stent improvements and more large scale studies are needed to make this a more routine procedure for obstructive strictures in the future.

Lastly, endoscopic stricturotomy has been recently investigated. In this procedure, a needle knife is used to cut the stricture using electroincision or electrocauterization [31]. Data was retrospectively reviewed from 85 patients treated with endoscopic stricturotomy at Cleveland Clinic (Table 2). Immediate technical success with passage of the endoscope through the stricture was achieved in $100 \%$ of patients, but there was a $4 \%$ rate of adverse events with 9 patients experiencing bleeding requiring blood transfusions and 1 perforation. Furthermore, $15 \%$ of the patients ultimately required surgical intervention. Endoscopic stricturotomy could potentially be an effective endoscopic technique in the future, but currently requires extensive training and expertise that limits its generalizability. Given the high success rate and low complication rate of balloon dilation, we recommend that endoscopic stricturotomy, like SEMS, be reserved for patients that have failed balloon dilation and are not ideal surgical candidates.

While there are several novel endoscopic techniques emerging for the treatment of endoscopic strictures, surgery remains the preferred approach for patients with multiple strictures, strictures associated with fistula or abscess, and long and angulated strictures [17]. An individualized approach should be taken focusing on the patient's anatomy, goals, and symptoms.

\section{Conclusions}

Crohn's disease is a complex disease that can progress in a penetrating and fibrostenotic fashion. Even though medical therapy is evolving at a fast pace, there is still a need for endoscopic therapy to bridge the gap between medical and surgical treatments. Advanced endoscopic techniques can evaluate previously inaccessible parts of the small bowel and treat fibrostenotic complications. Established techniques include video capsule endoscopy, small bowel enteroscopy, and balloon dilation. Novel endoscopic techniques such as mesenchymal stromal cells, intralesional injection, self expanding stents, and endoscopic stricturotomy are also being investigated but need more large scale studies prior to wide spread adoption. Interventional treatment of inflammatory bowel disease is a new and exciting field that will only continue to grow and expand in the future.

\section{Author Contributions}

All authors contributed equally to this literature review including drafting, critical revision, editing, and final approval.

\section{Funding}

There are no financial relationships relevant to this publication.

\section{Competing Interests}

The authors have declared that no competing interests exist. 


\section{References}

1. Thia KT, Sandborn WJ, Harmsen WS, Zinsmeister AR, Loftus EV. Risk factors associated with progression to intestinal complications of Crohn's disease in a population-based cohort. Gastroenterology. 2010; 139: 1147-1155.

2. Louis E, Collard A, Oger AF, Degroote E, Aboul Nasr El Yafi FA, Belaiche J. Behaviour of Crohn's disease according to the Vienna classification: Changing pattern over the course of the disease. Gut. 2001; 49: 777-782.

3. Dionisio PM, Gurudu SR, Leighton JA, Leontiadis GI, Fleischer DE, Hara AK, et al. Capsule endoscopy has a significantly higher diagnostic yield in patients with suspected and established small-bowel Crohn's disease: A meta-analysis. Am J Gastroenterol. 2010; 105: 1240-1248.

4. Lazarev M, Huang C, Bitton A, Cho JH, Duerr RH, McGovern DP, et al. Relationship between proximal Crohn's disease location and disease behavior and surgery: A cross-sectional study of the IBD Genetics Consortium. Am J Gastroenterol. 2013; 108: 106-112.

5. Cave D, Legnani $P$, de Franchis $R$, Lewis BS, ICCE. ICCE consensus for capsule retention. Endoscopy. 2005; 37: 1065-1067.

6. Jensen MD, Nathan T, Rafaelsen SR, Kjeldsen J. Diagnostic accuracy of capsule endoscopy for small bowel Crohn's disease is superior to that of MR enterography or CT enterography. Clin Gastroenterol Hepatol. 2011; 9: 124-129.

7. Kopylov U, Nemeth A, Koulaouzidis A, Makins R, Wild G, Afif W, et al. Small bowel capsule endoscopy in the management of established Crohn's disease: Clinical impact, safety, and correlation with inflammatory biomarkers. Inflamm Bowel Dis. 2015; 21: 93-100.

8. Kopylov U, Yablecovitch D, Lahat A, Neuman S, Levhar N, Greener T, et al. Detection of small bowel mucosal healing and deep remission in patients with known small bowel Crohn's disease using biomarkers, capsule endoscopy, and imaging. Am J Gastroenterol. 2015; 110: 1316-1323.

9. Yamamoto $H$, Sekine $Y$, Sato $Y$, Higashizawa $T$, Miyata $T$, lino $S$, et al. Total enteroscopy with a nonsurgical steerable double-balloon method. Gastrointest Endosc. 2001; 53: 216-220.

10. Lichtenstein GR, Loftus EV, Isaacs KL, Regueiro MD, Gerson LB, Sands BE. ACG Clinical guideline: Management of Crohn's disease in adults. Am J Gastroenterol. 2018; 113: 481-517.

11. Rahman A, Ross A, Leighton JA, Schembre D, Gerson L, Lo SK, et al. Double-balloon enteroscopy in Crohn's disease: Findings and impact on management in a multicenter retrospective study. Gastrointest Endosc. 2015; 82: 102-107.

12. Jang HJ, Choi MH, Eun CS, Choi H, Choi KY, Park DI, et al. Clinical usefulness of double balloon enteroscopy in suspected Crohn's disease: The KASID multi-center trial. Hepatogastroenterology. 2014; 61: 1292-1296.

13. Schulz C, Mönkemüller K, Salheiser M, Bellutti M, Schütte K, Malfertheiner P. Double-balloon enteroscopy in the diagnosis of suspected isolated Crohn's disease of the small bowel. Dig Endosc. 2014; 26: 236-242.

14. Despott EJ, Gupta A, Burling D, Tripoli E, Konieczko K, Hart A, et al. Effective dilation of smallbowel strictures by double-balloon enteroscopy in patients with symptomatic Crohn's disease (with video). Gastrointest Endosc. 2009; 70: 1030-1036. 
15. Pohl J, May A, Nachbar L, Ell C. Diagnostic and therapeutic yield of push-and-pull enteroscopy for symptomatic small bowel Crohn's disease strictures. Eur J Gastroenterol Hepatol. 2007; 19: 529-534.

16. Baars JE, Theyventhiran R, Aepli P, Saxena P, Kaffes AJ. Double-balloon enteroscopy-assisted dilatation avoids surgery for small bowel strictures: A systematic review. World J Gastroenterol. 2017; 23: 8073-8081.

17. Shen B, Kochhar G, Navaneethan U, Liu X, Farraye FA, Gonzalez-Lama Y, et al. Role of interventional inflammatory bowel disease in the era of biologic therapy: A position statement from the Global Interventional IBD Group. Gastrointest Endosc. 2019; 89: 215-237.

18. Chen M, Shen B. Endoscopic therapy in Crohn's disease: Principle, preparation, and technique. Inflamm Bowel Dis. 2015; 21: 2222-2240.

19. Rieder F, Latella G, Magro F, Yuksel ES, Higgins PD, Di Sabatino A, et al. European Crohn's and colitis organisation topical review on prediction, diagnosis and management of fibrostenosing Crohn's disease. J Crohns Colitis. 2016; 10: 873-885.

20. Bettenworth D, Gustavsson A, Atreja A, Lopez R, Tysk C, van Assche G, et al. A pooled analysis of efficacy, safety, and long-term outcome of endoscopic balloon dilation therapy for patients with stricturing Crohn's disease. Inflamm Bowel Dis. 2017; 23: 133-142.

21. Lian L, Stocchi L, Remzi FH, Shen B. Comparison of endoscopic dilation vs surgery for anastomotic stricture in patients with Crohn's disease following ileocolonic resection. Clin Gastroenterol Hepatol. 2017; 15: 1226-1231.

22. Gustavsson A, Magnuson A, Blomberg B, Andersson M, Halfvarson J, Tysk C. Endoscopic dilation is an efficacious and safe treatment of intestinal strictures in Crohn's disease. Aliment Pharmacol Ther. 2012; 36: 151-158.

23. Atreja A, Aggarwal A, Dwivedi S, Rieder F, Lopez R, Lashner BA, et al. Safety and efficacy of endoscopic dilation for primary and anastomotic Crohn's disease strictures. J Crohns Colitis. 2014; 8: 392-400.

24. Lian L, Huang Q, Zhang L, Qin H, He X, Ke J, et al. Anti-fibrogenic potential of mesenchymal stromal cells in treating fibrosis in Crohn's disease. Dig Dis Sci. 2018; 63: 1821-1834.

25. East JE, Brooker JC, Rutter MD, Saunders BP. A pilot study of intrastricture steroid versus placebo injection after balloon dilatation of Crohn's strictures. Clin Gastroenterol Hepatol. 2007; 5: 1065-1069.

26. Di Nardo G, Oliva S, Passariello M, Pallotta N, Civitelli F, Frediani S, et al. Intralesional steroid injection after endoscopic balloon dilation in pediatric Crohn's disease with stricture: $A$ prospective, randomized, double-blind, controlled trial. Gastrointest Endosc. 2010; 72: 12011208.

27. Hendel J, Karstensen JG, Vilmann P. Serial intralesional injections of infliximab in small bowel Crohn's strictures are feasible and might lower inflammation. United European Gastroenterol J. 2014; 2: 406-412.

28. Matsuhashi N, Nakajima A, Suzuki A, Yazaki Y, Takazoe M. Long-term outcome of non-surgical strictureplasty using metallic stents for intestinal strictures in Crohn's disease. Gastrointest Endosc. 2000; 51: 343-345.

29. Loras C, Pérez-Roldan F, Gornals JB, Barrio J, Igea F, González-Huix F, et al. Endoscopic treatment with self-expanding metal stents for Crohn's disease strictures. Aliment Pharmacol Ther. 2012; 36: 833-839. 
30. Andujar XLC, Gornals JB, Sanchiz V, Brullet E, Sicilia B, Naranji A, et al. Comparative, randomized and prospective multicentric study on the endoscopic treatment of Crohn's disease related strictures: Seld-expandable metal stents vs balloon dilation: The PROTDILAT study. Endoscopy. 2017; 49: 1129-1194.

31. Lan N, Shen B. Endoscopic stricturotomy with needle knife in the treatment of strictures from inflammatory bowel disease. Inflamm Bowel Dis. 2017; 23: 502-513.

32. Navaneethan U, Lourdusamy V, Njei B, Shen B. Endoscopic balloon dilation in the management of strictures in Crohn's disease: A systematic review and meta-analysis of nonrandomized trials. Surg Endosc. 2016; 30: 5434-5443.

33. Morar PS, Faiz O, Warusavitarne J, Brown S, Cohen R, Hind D, et al. Systematic review with meta-analysis: Endoscopic balloon dilatation for Crohn's disease strictures. Aliment Pharmacol Ther. 2015; 42: 1137-1148.

34. Thienpont C, D'Hoore A, Vermeire S, Demedts I, Bisschops R, Coremans G, et al. Long-term outcome of endoscopic dilatation in patients with Crohn's disease is not affected by disease activity or medical therapy. Gut. 2010; 59: 320-324.

35. Reutemann BA, Turkeltaub JA, Al-Hawary M, Waljee AK, Higgins PDR, Stidham RW. Endoscopic balloon dilation size and avoidance of surgery in stricturing Crohn's disease. Inflamm Bowel Dis. 2017; 23: 1803-1809.

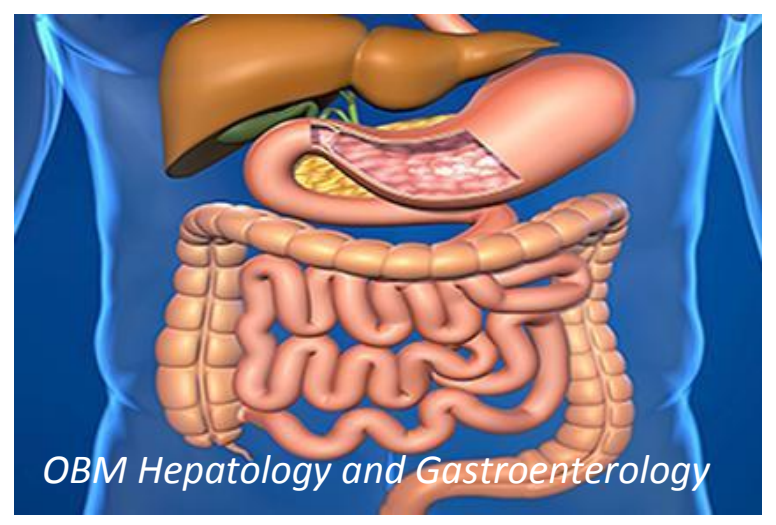

Enjoy OBM Hepatology and Gastroenterology by:

1. Submitting a manuscript

2. Joining in volunteer reviewer bank

3. Joining Editorial Board

4. Guest editing a special issue

For more details, please visit: http://www.lidsen.com/journals/hg 